\title{
HVMANITAS
}

\section{Representações do feminino no drama satírico: as ninfas, amenas e sombrias}

\section{Autor(es): $\quad$ Barbosa, Tereza Virgínia Ribeiro}

Publicado por: Faculdade de Letras da Universidade de Coimbra, Instituto de Estudos

URL

persistente: URI:http://hdl.handle.net/10316.2/27920

DOI: $\quad$ DOI:http://dx.doi.org/10.14195/2183-1718_60_6

Accessed : $\quad$ 26-Apr-2023 10:17:42

A navegação consulta e descarregamento dos títulos inseridos nas Bibliotecas Digitais UC Digitalis, UC Pombalina e UC Impactum, pressupõem a aceitação plena e sem reservas dos Termos e Condições de Uso destas Bibliotecas Digitais, disponíveis em https://digitalis.uc.pt/pt-pt/termos.

Conforme exposto nos referidos Termos e Condições de Uso, o descarregamento de títulos de acesso restrito requer uma licença válida de autorização devendo o utilizador aceder ao(s) documento(s) a partir de um endereço de IP da instituição detentora da supramencionada licença.

Ao utilizador é apenas permitido o descarregamento para uso pessoal, pelo que o emprego do(s) título(s) descarregado(s) para outro fim, designadamente comercial, carece de autorização do respetivo autor ou editor da obra.

Na medida em que todas as obras da UC Digitalis se encontram protegidas pelo Código do Direito de Autor e Direitos Conexos e demais legislação aplicável, toda a cópia, parcial ou total, deste documento, nos casos em que é legalmente admitida, deverá conter ou fazer-se acompanhar por este aviso.

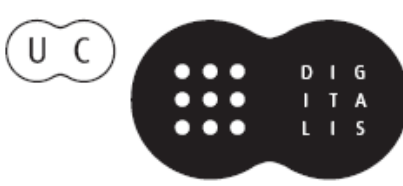


humanitas

\section{Vol. LX}

IMPRENSA DA UNIVERSIDADE DE COIMBRA

COIMBRA UNIVERSITY PRESS 


\title{
REPRESENTAÇÕES DO FEMININO NO DRAMA SATÍRICO: AS NINFAS, AMENAS E SOMBRIAS*
}

\author{
Tereza Virgínia Ribeiro Barbosa \\ Universidade Federal de Minas Gerais / CNPq \\ virginiarb@yahoo.com.br
}

\begin{abstract}
Resumo
Pretendemos mostrar a personificação do espaço em um drama satírico de Sófocles. Focalizaremos as grutas e as ninfas e discutiremos o espaço dedicado a estas deidades ocupando-nos particularmente dos versos 267-8 de Ichneutas e postulando que a leitura que subentenda a personificação provoca ambigüidade e riso.

A fusão de imagens das ninfas, grutas e mulheres usada por outros autores, nessa tentativa, argumentarão a nosso favor. $O$ autor escollido para exemplificação juntamente com Sófocles é o romancista brasileiro, Erico Verissimo em Incidente em Antares.
\end{abstract}

Palavras-chave: ninfas, gruta, natureza, mulher.

\section{Abstract}

In this article, we intend to show the personification of space in a Sophocles' satyr play and try to focus on the personification of nymphs in caves. Specifically verses $267-8$ of Ichneutae are analyzed; we propose that the poet's finality is to provoke laugh.

The fusion of images of nymphs, caves and women is used by other authors and help us in our attempt to affirm that the same strategy is used in a Brazilian novel, Incidente em Antares, of Erico Verissimo.

Keywords: nymphs, cave, nature, women.

* Pesquisa realizada sob os auspícios do CNPq - Brasil. 
Nos vários textos gregos remanescentes, as ninfas são criaturas muito diversas e surgem, frequentemente, no coletivo. Organizadas em bandos numerosos, o problema para quem as quer conhecer tem início desde sua nomeação, visto que a palavra nymphe pode ocorrer tanto como substantivo comum aplicado a mulheres quanto como termo designador de uma categoria particular de divindade. Desse modo e já de início, elas são tanto representações de um feminino jovem, fértil e vigoroso, quanto materialização de entidades espirituais em espaços naturais variados, alguns agradabilíssimos, outros assustadores, outros ainda, excitantes.

Pretendemos observar as ninfas, a partir de dois versos do drama satírico Ichneutas, de Sófocles, e mostrar que elas veiculam uma concepção de espaço que permanece fecunda nos textos literários contemporâneos. Limitar-nos-emos a pequenos trechos, alusões e sugestões que estão $\mathrm{em}$ frases e idéias que tomamos de Hesíodo a Longo e a Porfírio e que chegam até a literatura brasileira no romance Incidente em Antares de Érico Verissimo.

O processo que focalizaremos para estudá-las é tão antigo quanto o homem e talvez passe despercebido, embora continue sendo, como forma de criação poética, oportuna reintegração e revalorização de espaços os quais provocam, desde sempre, interesse, encanto, medo, sentimento de posse, de dominação e de entrega. Tais espaços são as montanhas, as águas e as grutas vistas na perspectiva de "moradas das ninfas", o seu local de pouso e refúgio, mas também seu próprio corpo, o meio pelo qual elas se manifestam e se ligam aos seres humanos. Referimo-nos, portanto, ao processo tecnicamente chamado de personificação, o qual, por sua vez, é uma variante da alegoria e será focalizado para delinear o imaginário em relação a um espaço específico: as grutas, cavernas, furnas, antros e tudo que se relaciona com os ocos da terra.

No entanto poder-se-á retrucar que o tratamento de coisas concretas, de noções abstratas, espirituais e ou coletivas como pessoas se enfraquece numa literatura em que deuses são antropomórficos e interagem com humanos. Mas com as ninfas é diferente. Em primeiro lugar: as ninfas morrem; em segundo lugar, elas parecem ser mais que uma categoria coletiva que representa o relacionamento de deuses e homens com a terra, a vegetação, as águas e o ar. De fato, elas são a corporificação do sagrado profanado e assimilado pelo homem. Referimos-nos, agora, à teoria do filósofo italiano Giorgio Agamben em Profanaçôes (G. Agamben 2005: 99 e 123) e mais especificamente ao capítulo Elogio da profanação. Agamben dirá, no referido capítulo, que à religião não se opõem a incredulidade e a 
indiferença, mas a negligência, a qual, segundo ele, é uma atitude distraída, desligada frente às coisas, uma banalização geradora do pornográfico. O que seria, na verdade, uma prostituição. De acordo com o filósofo, a profanação, ao contrário da prostituição, é o uso consciente e a reintegração do sagrado no jogo da vida. A utilização desse conceito de Agamben nos parece muito oportuna, pois na era da realidade virtual, da internet, era de forças e poderes encerrados em si mesmos sem o desejo de realização, os cenários, os espaços e o tempo às vezes se anulam, às vezes tornam-se meras ilusões que podem nos levar para o lugar do descaso, aquele que é distante da experiência corporal e visceral, tão importante, no nosso ponto de vista, para a realização pessoal.

Pretendemos, portanto, mostrar nesse pequeno estudo como ilusão, virtualidade e realidade visceral formam um conjunto interessante no mito das ninfas-cavernas, sobretudo, nos dois versos selecionados do drama satírico sofocleano escolhido.

Mas longe de nós condenar a ilusão e a virtualidade. O teatro se faz através delas. Não queremos afirmar, jamais, que os gregos do séc. V a.C. contexto de nossa análise - não estariam imersos na discussão dessas questões; aliás, o engano dos sentidos e da mente é tema de reflexão especial para eles que culmina no movimento sofistico. Entretanto, se levarmos em conta um texto como Bacantes de Eurípides, haveremos de entender que a ação ilusória no teatro grego é também visceral.

Segundo J. Clay, (2003: 97) as ninfas parecem ser, na Teogonia de Hesíodo, ancestrais dos humanos oriundos da união dos gigantes e das Melíades, as nascidas do respingo do sangue de Urano em Gaia, irmãs das Erínias. Desse modo, ninfas nem sempre são benfazejas: Equidna, por exemplo, é modelo de perversidade. Ela é descrita pelo poeta como uma terrível gruta-ninfa de olhos vivos, lindas faces e ânimo assustador de serpente. Carnívora, ela habita as covas da mãe terra (Teogonia 120, 295-300).

Mas aqui precisamos fazer um retrocesso temporal para melhor compreender a relação dos helênicos com a natureza e o espaço em que viviam. Para Hyde (1915: 70-74), a questão foi inaugurada por Humboldt, no segundo volume de sua obra Kosmos. O problema, para ele, se coloca a partir da hipótese de que os antigos tinham pouco apreço pela acidentada beleza da geografia mediterrânea e que o gosto pela grandeza e magnitude de suas montanhas e terras deitadas frente a um mar aberto e vigoroso seria uma projeção moderna sobre os antigos. Ainda segundo Hyde, citando Tozer e Ruskin, haveria no homem grego, de acordo com Tozer, um 
desprezo pelo cenário não cultivado. Ruskin, na mesma linha, afirma existir intimidação, medo e repulsa diante das densas e encrespadas florestas, das escarpadas montanhas e do descontrolado poder de adversidade de céu, mar e terra. Nesse percurso, aprazíveis para eles seriam somente os lugares controláveis e limitáveis: as poleis, as fontes, prados e bosques ensombrados os quais a vista pode conter e entender sem grandes surpresas, conjectura que é nossa vez de julgar: mais uma projeção de seu tempo.

Mas Hyde não compartilha das idéias dos colegas; seu artigo será destinado a realçar situações poéticas que contemplam o espaço acolhedor, sem, contudo, evitar comentar trechos que mostram a força do ambiente que curva, dobra e ameaça, como é o caso do Cáucaso no muito conhecido prólogo do Prometeu, de Ésquilo e de vários nomes de locais citados e predicados por adjetivos como: hostil, selvagem, agreste etc. Com essa metodologia, para mostrar um relacionamento afetivo do homem com seu espaço, Hyde arrola uma série de passagens de Homero em que nos deleitamos com a delicadeza - e também a magnitude terrível - que transparece no olhar do que vê a paisagem ao seu redor e manifesta seu sentimento no fascínio das descrições.

Deixando, entretanto, Homero, e à parte o encanto científico despertado já em Pausânias, Estrabão e outros geógrafos, vamos, por meio das intuições do pesquisador inglês, observar o espaço necessário para que as ninfas se coloquem representadas no texto do drama satírico. Vemos, porém, que não seria prudente tomarmos apenas um texto de quase cem anos como referência. Mais modernamente entendemos que a noção de espaço é histórica (Berquist 1999); é criada, formada, transformada e apagada pela cultura (Foucault 1967). Nessa complexidade de visões, continuamos a postular que o maior interesse do grego é o homem. Todavia, nesse ponto temos um diferencial: vamos tratar o espaço que, metaforizado no corpo de ninfas, interage com deuses e homens e, por causa de um duplo acesso (ao divino e ao humano), se torna um espaço mágico e epifânico, o qual, para não se manter intacto, isolado e esquecido, como sói acontecer com o sagrado, é profanado, isto é, devolvido ao uso comum (Agamben 2005: 105), faz parte do dia-a-dia e por isso se revela mais real, afável, insubstituível e inalienável.

A idéia está presente em um pequeno trecho de Incidente em Antares (Verissimo 1994: 44-45), romance do escritor Érico Verissimo onde Tibério Vacariano, olhando para a pradaria gaúcha, se põe a pensar na cidade do Rio de Janeiro. Cito o trecho: 


\begin{abstract}
"Algumas vezes, porém, quando estava em cima dum cavalo, na estância, parando rodeio ou simplesmente cruzando uma invernada, passavam-lhe pelo campo da memória imagens fugidias como essas que a gente mal vê pela janela dum trem em movimento. O Corcovado... a pedra da Gávea... ondas batendo na pedra do Arpoador... as areias de Copacabana... caras, coxas, seios, pernas, nádegas de mulheres, sob pára-sóis coloridos... peles reluzentes de óleo de coco... e o sol e o mar e as montanhas... "Pota que me pariu! Que é que eu estou fazendo aqui neste fim de mundo, fedendo a creolina e levando esta vida de bagual?"
\end{abstract}

O que interessa, particularmente, são os termos, ou antes o sutil e deslizante deslocamento que se opera: Corcovado... a pedra da Gávea... pedra do Arpoador... as areias de Copacabana... caras, coxas, seios, pernas, nádegas de mulheres, sol, mar e as montanhas...

Pelo afeto, o brasileiro, em sua grande maioria, é povo praiano. Mesmo os mineiros, encravados no umbigo de muitas montanhas, buscam as areias e dunas ardentes do Espírito Santo, os montes e praias do Rio de Janeiro, as praias fluviais do São Francisco, as cachoeiras fabulosas das serras e matas tropicais, nestes contextos, há uma relação amorosa efetiva a qual se pode observar através de um fluxo que parece fazer escoar palavras que designam uma paisagem concreta que desemboca no corpo feminino. A transição que Verissimo realiza (Corcovado, Gávea, Arpoador, Copacabana e corpo humano feminino) é tradição muito antiga, já apontada por Hesíodo, com, por exemplo, a expressão terra de amplos seios (Teogonia, 117) e por Aristófanes (Lisístrata, 87-88). À moda brasileira, o escritor gaúcho desenvolve sua analogia ao longo da relação amorosa de Tibério e Cleo em detalhes pitorescos, dentre os quais destaco um personagem desbravador destemido do qual o velho fazendeiro se apropria: Blau Nunes, um campeiro que " $[\mathrm{t}]$ inha aprendido com o fantasma dum padre renegado o caminho da furna do Jarau, onde existia um tesouro escondido, e guardado pelos bichos e assombrações mais horríveis." (Verissimo 1994: 69)

Aqui temos uma síntese de nossa proposta: corpo humano das ninfas é o espaço geográfico que oculta um tesouro escondido e vigiado por assombrações (entendemos assombrações como tudo que gera assombro). Nesse sentido, o drama satírico é, por excelência, um lugar poético onde surgem as entidades femininas ninfas (a saber, as montanhas, as fontes e as grutas) relacionando-se, de forma privilegiada, com homens deuses e 
híbridos. Descuidaremos das ninfas dos bosques, dedicar-nos-emos as orestíades e dentre essas, especificamente, a Maia e Cilene, duas deidades que aparecem, uma citada, a outra como personagem, no drama satírico Ichneutas, de Sófocles. Elas representam, como o comum das ninfas, os recantos íntimos de pequenez aconchegante, mas de profundeza assustadora. Vamos associá-las, seguindo passos de Verissimo, à história da Salamanca do Jarau de Blau Nunes, vinculando-as a Tibério e a Cleo.

Tomamos, apenas, dois versos da obra de Sófocles: vv. 267-8, e informamos que o trecho está muito danificado. Hunt e Wilamowitz completam o

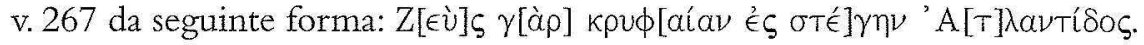

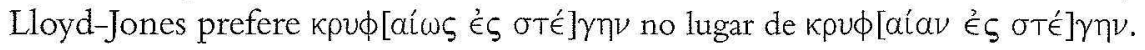

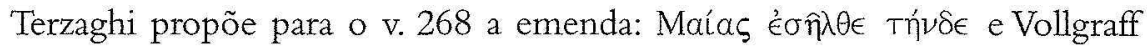

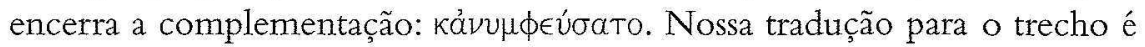
a que se segue:

"Pois Zeus, às ocultas, para a gruta" da filha de Atlante, Maia, veio, penetrou nesta .... e a ela uniu-se."2

Vamos investigar a metáfora que subjaz no passo. Para tanto, retomaremos Homero (Od. 13. 96-112). No passo somos informados que as grutas das ninfas eram consideradas entradas tanto para o mundo subterrâneo como para o celestial, ou seja, elas indicam passagens duplas, para a vida e para a morte.

Além de Homero podemos recorrer ainda a um autor tardio, Longo, com o intuito de identificar um imaginário preservado por séculos. O poeta abre seu romance Dafnis e Cloé, com a descrição de um ex-voto consagrado a Eros, ninfas e Pã, um quadro esplendidamente pintado. Pelo proêmio fica estabelecido o tom da narrativa e já no primeiro capítulo encontraremos

${ }^{1}$ Segundo MacLachlan, (Kore as Nymph, not Daughter, http://wrww.stoa.org/ diotimalessays/fc04/ MacLachlan.html) em passagens freqüentes na literatura, as ninfas habitam grutas, entradas para o mundo subterrâneo, acompanham o cortejo fúnebre do pai de Andrômaca. cf. Homero (Od. 13. 96-112; Il. 6. 420). Moradoras de lugares escondidos, uma especialidade dessas divindades é gerar seres que distanciam da normalidade, tais como Polifemo, os silenos e os centauros. (cf. Díez Platas 1996: 73).

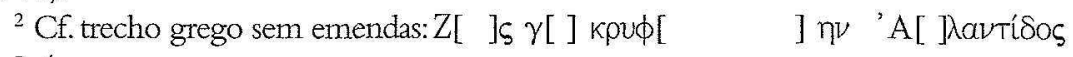
l ] $\in$ ÚøaTo. 
Dafnis, um menino abandonado no bosque e nutrido por um cabra. Acharemos também a menina Cloé no mesmo bosque, em situação semeIhante, todavia, de forma mais protegida, ou seja, numa gruta de ninfas, um enorme rochedo redondo por fora e oco por dentro, um lugar de particular beleza, onde jorrava uma fonte de águas abundantes (livro 1, \$4). Cloé tinha uma ovelha como nutriz. Nascidos ambos sob o signo das deidades dos bosques, unidos por Eros e assombrados pelo estigma de Pã, para o par adolescente, as grutas, a vegetação, os ecos, e as fontes estabelecem uma paisagem ideal para o sentimento amoroso que se vai desenvolver e fazer deles, crianças que vão atingir a maturidade lenta e ingenuamente, amantes perenes.

Associando a história de Cilene, sugestivas imagens de Hesíodo e Aristófanes, o ambiente propício para o amor evocado por Longo e a brincadeira de Tibério e Cleo podemos propor uma interpretação licenciosa e divertida dos versos 267-8 de Sófocles em Ichneutas.

Personagem destacada do drama satírico de Sófocles, 'Cilene' é homônimo de uma montanha de aproximadamente 8.000 pés de altura em medida de tempos modernos, pois há muita variação nos índices que apresentam Gémino, Estrabão, Apolodoro, Xenágoras (Hyde 1915: 75). Enquanto ninfa, ela é caracterizada pelos sátiros (Ichneutas 41) com epítetos comuns a todos os habitantes das florestas e montanhas: montesa como as cabras, suas companheiras (Od. 9. 152-155). A relação entre elas parece estar na função do aleitamento, apontada por Longo e comprovada no mito de Zeus o qual fontes antigas registram. Diez Platas (1996: 29, 32, n.19 e 34) afirma que, em geral, os epítetos utilizados para as ninfas referem-se exclusivamente a suas qualidades fisicas. Platas afirma que nos hinos homéricos encontramos outros vários qualificadores e entre eles, o que aqui nos interessa, aqueles formados com bathy-componente que indica profundidade ou maciez para penetração e com kólpos termo que pode levar para o campo semântico da nutriz. Algumas expressões cunhadas por Ariano Suassuna, em A Pedra do Reino e O rei degolado, parecem-nos muito adequadas para uma tradução deste epíteto: peitos brandos ou peitos macios $^{3}$. Dessa forma, passamos a entender as ninfas como deidades

${ }^{3}$ Seguem dois exemplos de contexto de utilização: Escutem, pois, nobres Senhores e belas Damas de peitos brandos, minha terrivel história de amor e de culpa; de sangue e de justiça; de sensualidade e violência; de enigma, de morte e disparate; (...). (A pedra do 
habitantes de montanhas de peitos macios, relevos penetráveis. Bathýkolpos, entretanto, não ocorre nos versos que nos chegaram de Ichneutas, contudo um de seus componentes é utilizado por Sófocles em bathýzonos, um composto de bathy- e zone-. Se tomamos a indicação de Liddell-Scott, zone- como cinto; ou de Bailly, como cintura, objeto que contorna a cintura, podemos traduzir o epíteto que predica as ninfas por cinta macia ou cinta ajustada ou ainda se associarmos zone- e bathy- à leitura de Vivante (1982: 115) que confere ao termo o sentido de que se pode mergulhar, penetrar, lançar-se ou emergir-se, teremos que Cilene é uma ninfa que se pode enlaçar. A reflexão pretende mostrar que, ao tratar de ninfas, estamos entrando em um campo semântico que remete para curvas, volumes, abundância e penetrações, termos que, na analogia de Verissimo, remetem para a exuberância feminina.

Outro autor tardio, Porfirio, no El antro de las ninfas, comentando a já referida gruta de Ítaca, consagrada às ninfas Naiádes, expressará a abundância do local marcado pelo fluxo contínuo das águas. As passagens duplas (do lado de Bóreas acessivel aos mortais e do lado de Noto acessível aos imortais) caracterizam, para o filósofo, as ninfas-grutas como seres intermediários, canais para mundos opostos. Durante os $\mathbb{S} 3,5$ e 6 , Porfírio discute, para tal gruta, a união de atributos aparentemente contrários, a saber, amena e sombria, em grego epératon eeroidés. Porfirio explica que essas informações não são incompatíveis: a forma exterior e a superficie são agradáveis, o interior e a profundidade, no entanto, são sombrios ( $\$ 6)$. Para ele a gruta é símbolo do mundo sensível, dos poderes invisíveis presentes nesse mundo. Assim, associando ninfa e água, o fllósofo (\$8) cita o Hino a Apolo e afirma que as ninfas proporcionam aos mortais incessantes ondas de doces correntes. Em sentido estrito, ele acrescenta que as Náiades, que presidem as águas, designavam com seu nome todas as almas que 'descem' para a 'encarnação' e menciona ainda Heráclito que afirmara que as almas que vêm para serem geradas se tornam úmidas e que o sangue e o sêmen thes são amáveis $(\$ 10)$, por essa razão a concepção dos seres, vegetais, humanos, divinos ou híbridos, se dá na umidade.

Concluindo, o filósofo tardio do séc. III, oriundo da cidade de Tiro, afirmará que todas as grutas são consagradas às almas e às ninfas $(\$ 13)$.

reino: p. 35). De fato, nobres Senhores e belas Damas de peitos macios, o escudo que acabei de descrever era (...) (A pedra do reino: p. 47). 
Ele explica alegoricamente e diz que a carne se forma em torno aos ossos, que são como pedra nos seres vivos $(\$ 14)$; e que ele próprio segue os passos de Ferécides de Siro, quando fala de ocos, orificios grutas, entradas e portas, simboliza enigmaticamente a geração das almas $(\$ 31)$.

Mas voltando ao nosso ponto de partida: a narração do nascimento do filho de Zeus e da ninfa Maia, história que tem seus antecedentes no Hino Homérico a Hermes e que visa à exaltação do deus malandro; pela observação de somente dois versos, cremos que podemos afirmar que no contexto de Ichneutas, Maia, além do campo semântico de nascimentos e aleitamentos, integra uma das mais marcantes façanhas sexuais ${ }^{4}$ de seu parceiro, Zeus. Cilene, por seu turno, no decorrer da peça é assediada pelos sátiros. Essas parcerias são, de resto, motivo suficiente para explicar o entorno erótico que provocam essas deidades. Com a relação íntima e duradoura com deuses e híbridos, retomamos a discussão do despertar de sentimentos diante do cenário natural grego e obviamente, do brasileiro. Apoiados nos vestígios de textos gregos do mundo antigo, com incursões ao Del antro de las ninfas, de Porfírio e ao Dafnis e Cloé de Longo, postulamos que a união com a ninfa, materializada nos encontros amorosos de cavernas subterrâneas, concretiza o espaço de sedução onde se dará a expectativa de uma experiência espantosa. O fruto dessa união é a realização da profanação definida nos termos de Agamben, ou seja, a ninfa - uma divindade nitidamente atrelada à Natureza - em sua forma antropomórfica, aproxima-se da humanidade a ponto de se tornar alegoria do ato amoroso. Para finalizar, passemos, outra vez, a Verissimo (1994: 66-69). com seu personagem Tibério, o qual descreve com essas palavras a sua amante Cleo:

“(...) a rapariga mais linda do mundo. Dezessete aninhos (...) Morena jambo (...)"

"(...) que habita o bordel de Venusta, um lugar que ficava numa ruela pouco iluminada e tinha nos fundos do seu quintal um portão que dava para um terreno baldio - espécie de entrada secreta ou pelo menos discreta...

${ }^{+}$De fato, os templos dedicados às ninfas, segundo Lloyd-Jones (2003: 157), apresentavam relevos com perseguições dos sátiros a essas divindades. $\mathrm{O}$ helenista inglês comenta que as proezas com a lança descritas, frequentemente, pelos sátiros são triunfos alcançados nesse campo de batalha, o leito. 
Que fềmea mais bem-feita de corpo! Uma potranca de raça - cabocla de pele acetinada cor de areia úmida, seios miúdos, quadris estreitos, delicada como uma flor... Em cima dela sentia-se com vinte anos menos.

O cheiro dela ficava nas suas narinas, nos seus dedos, na sua pele, entranhado em todo o seu corpo."

A assimilação 'natureza e corpo humano' permite a Verissimo a narrativa do já apresentado Blau Nunes, a qual se estabelece numa espécie de 'alegoria atual' da união amorosa que transcrevemos com cortes:

"-Faz de conta que aqui vai o Blau Nunes..."

"Com os dedos indicador e médio da mão direita imitou as pernas dum homem a caminhar. Blau Nunes percorreu o braço e o ombro de Cleo, devagarinho, pisando forte.

- De repente Blau avista um cerro...E os dedos de Tibério escalam..."

"(...) - Então Blau Nunes desce do cerro e começa a andar por uma linda várzea...

E agora os dedos de Tibério caminham pelo ventre levemente côncavo da menina, com lenta volúpia.

- De repente Blau Nunes avista um capão..."

"(...) Mas Blau Nunes continua a andar... lá dentro está a entrada da Salamanca, do tesouro..."

É assim que, no final do romance de Verissimo, Tibério, imitando as pernas do campeiro da lenda, escala com os dedos "os seios de Cleo - que de cerros se haviam transformado em montanhas, por artes da fisiologia mancomunada com o tempo - e depois percorre "em passos lentos o ventre, não mais uma planície com uma suave depressão, mas já uma coxilha." (Verissimo 1994: 479).

Concluindo e costurando as imagens dos poetas, propomos uma leitura do passo de Ichneutas que julgamos bem apropriada para o gênero, aquela que se constrói a partir da escolha de um vocabulário ambíguo e malicioso; se, em analogia com o corpo feminino, interpretarmos a fala de Cilene. Dessa forma, quando a ninfa de 'cintura macia' descreve como Zeus, descendo à gruta, penetra, às ocultas, o espaço onde habita Maia e concebe seu filho Hermes, todo o trecho pode ser entendido com um gosto picante que ultrapassa a história conhecida. Aplicando a reflexão sobre o tratamento do espaço real, que é ao mesmo tempo, pelas urgências ecológicas sagrado, deduzimos que apenas a profanação o tornará intimo, 
amado e possuído. E se, segundo Adrados ${ }^{5}$, a ninfa é uma menina na cabeça e uma mulher corpo abaixo, a natureza, a montanha e as grutas, sendo ninfa, ela não deve jamais ser violada, somente profanada.

\section{Referências}

G. Agamben (2005), Profanaciones. Buenos Aires.

T.A. Allen (1989), Homeri opera. Tomo I e II. (ed.). Oxford.

Floyd G. Ballentine (1904), "Some Phases of the cult $f$ the nymphs", Harvard Studies in Classical Philology 15: 77-119.

J. L. BeRquist (1999), "Theories of Space and Construction of the Ancient World", http://www.case.edu/affil/GAIR/papers/99papers/jberquist.html, consultado em 3 de Abril de 2008.

J. S. Clay (32006), Hesiod's Cosmos. Cambridge.

M. F. Dízz Platas (2000), "Naturaleza y femineidad. Los epítetos de las Ninfas en la épica griega arcaica" CFC: egi 10:19-39.

(1996), Las ninfas en la literatura y en el arte de la Grécia arcaica. Tese. Universidad Complutense de Madrid.

A. L. Eire (2000), "Reflexiones sobre la lengua del drama satírico”, Humanitas 52: 91-122.

M. Foucault (1967), "Des espaces autres, Hétérotopies", http://foucault.info/ documents/heteroTopia/foucault.heteroTopia.fr.html, consultado em 3 de Abril de 2008.

G. P. GOOLD (1982), Hesiod, The Homeric hymns and homerica. London.

M. GRIfrith (2005), "Satyrs, citizens, and self-representation", in G. W. M. Harrison (ed.), Satyr drama: tragedy at play. Swansea, 161-199.

F. S. HalliwelL (1991), "The uses of laughter in greek culture", Classical Quarterly 41: $279-296$.

W.W. HYDE (1915), "The ancient appreciation of mountain scenery", The Classical Joumal 11.2: 70-84.

E. A. R. Jurado (1989), Porfirio, El antro de las ninfas de la Odisea. Madrid.

F. Létoublon (2004), "Sous le signe des Nymphes et de Pan. Daphnis et Chloé ou le paradoxe d'une culture raffinée sous les apparences d'une idylle rustique", L'information littéraire 54: 23-28.

\footnotetext{
${ }^{5}$ Diez Platas, 65, n. 32.
} 
H. Lloxd-Jones (2003), Sophodes' Fragments. London.

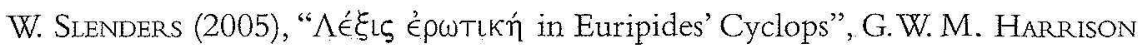
(ed.), Satyr drama: tragedy at play. Swansea.

W. B. StAnford (1987/1988), Odyssey of Homer. Vol. 1 e 2. London.

A. Suassuna (11977), História d'o Rei degolado nas caatingas do sertão. Rio de Janeiro. (2005), Romance d'A Pedra do Reino e o príncipe do sangue do vai-e-volta. Rio de Janeiro.

É. Verissimo ( $\left.{ }^{39} 1994\right)$, Incidente em Antares. Rio de Janeiro.

R. Di. Virgllio (52004), Longo Sofista, Dafnis e Cloe. Milano.

P. VIVANTE (1982), The epithets in Homer: a study in poetic values. New Haven/ London.

P. VOELKE (2000), "Formes et fonctions du risible dans le drame satyrique", in M.-L. Desclos (org.), Le rire des Gress. Grenoble, 95-108. 